\title{
A clinicoradiological scoring for management of acute subdural hematoma: a prospective study
}

\author{
Sachidanand Gautam ${ }^{1}$, Anubhav Sharma ${ }^{2}$, S.C. Dulara ${ }^{2}$ \\ ${ }^{1}$ Department of Neurosurgery, Government Medical College, Kota Rajasthan, INDIA \\ ${ }^{2}$ Department of Anesthesiology and Critical Care, Government Medical College, Kota Rajasthan, \\ INDIA
}

\begin{abstract}
Background: Acute subdural hematoma is the most common type of traumatic intra cranial hematoma accounting for $24 \%$ cases of severe head injuries and caries highest mortality. The aim of this study is to analyze the prognostic factors and to propose Neuro-clinical and radiological prognostic scoring system on the clinical spectrum and to evaluate the postoperative outcome and validate the same. Methods: This is a prospective Study which included 100 patients admitted in Government Medical College, Kota, Rajasthan from 01st Jan 2016 to 30 June 2017 with head injury and were diagnosed to have Traumatic Subdural Hemorrhage. A detailed clinical history, Physical examination, Computerized Tomography scan was performed in all patients and were divided into 2 groups; that is conservative or surgical interventional as per Neuro-clinical and radiological prognostic scoring system. Results: The maximum patients suffering from Subdural Hematoma were in the age group of 11-60 years with male predominance $72 \%$. The most common mode of injury was RTA with $68 \%$ of incidence. 36 out of 100 cases presented to hospital with GCS $<8$ while 44 patients showed improvement of GCS after resuscitation. Out of 100 cases, surgical approach was considered in 34 patients while remaining patients were managed conservatively. Pupillary reaction, Hypotension, CT scan findings that is, thickness of hematoma $>10 \mathrm{~mm}$ and midline shift of $>5 \mathrm{~mm}$, delay in interval between the surgery had greatly affected on outcome of patients. Conclusions: According to the results, use of Neuro-clinical and radiological prognostic scoring system is very useful in determining early intervention and also avoids unnecessary surgical intervention.
\end{abstract}

Key words: Clinicoradiological score, Neuro intervention, Subdural hematoma 


\section{Introduction}

Since the first attempts at aggressive neurosurgical intervention for traumatic acute subdural hematoma in the 1930's and 1940 's, the rate of mortality from this injury has ranged from $76 \%$ to $90 \%$. [7] Despite new technology and advent of new neuroradiological techniques and neurointensive monitoring and treatment, traumatic acute subdural hematoma remains one of the most lethal of all head injuries. Acute subdural post-traumatic haematoma's (SDH) continue to have a distressingly high morbidity and mortality. Clinical factors like presenting GCS, Pupils, Time to operative interval, Hemodynamics and co-morbidities plays a critical factor in overall outcome from acute subdural hematoma.

\section{Clinical Material and Methods}

This is a prospective observational study which included 100 patients admitted in government Medical College, Kota, Rajasthan from 01 st Jan 2016 to 30 June 2017 with head injury, diagnosed to have Traumatic subdural Hemorrhage. All cases were analyzed with respect to Age, sex, mode of injury, GCS at the time of presentation, post resuscitation GCS, pupillary anisocoria, focal neurological deficit, hemodynamic status, imaging findings of thickness of hematoma, midline shift, simple SDH or complicated SDH, Finding on repeat CT after $6 \mathrm{hrs}$, GCS at the time of discharge and at four weeks.

Patients were evaluates according to Neuro-clinical and radiological prognostic scoring system and were divided into two groups; conservative and operative.

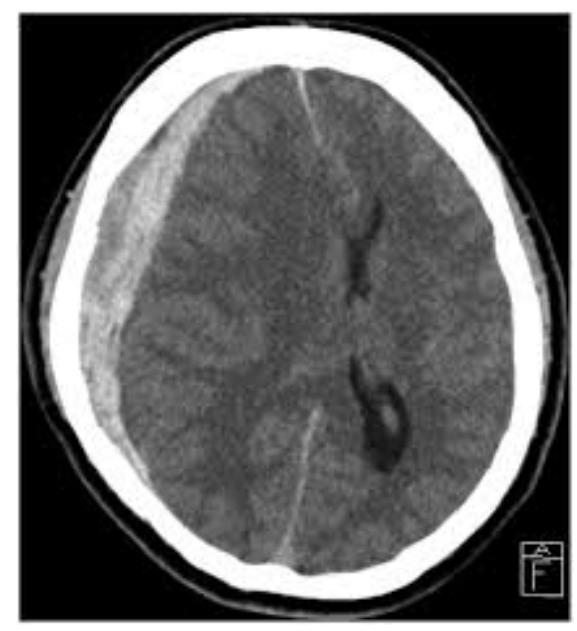

Criteria for surgical intervention were 1.Neuro-clinical and radiological prognostic score of 1-5 with hemodynamic stable patient and duration of arrival in hospital after trauma of less than 6 hrs with no co-morbid conditions. 2. Neuro-clinical and radiological prognostic score of 6-10 with hemodynamic stable patient and duration of arrival in hospital after trauma of less than $6 \mathrm{hrs}$ with no co-morbid conditions and hematoma thickness more than $10 \mathrm{~mm}$.

\section{Results}

One hundred cases of acute subdural hematoma out of 854 cases of head injury constituted $11.7 \%$. Youngest patient was 4 months old and oldest patient was 88 year old. $82 \%$ of patients were in second to sixth decade. This study showed that males are predominant as compared to females. Out of 100 cases, Males constituted 72\% whereas $28 \%$ were female (Table 1 ). 
Table 1 - Age and sex distribution

\begin{tabular}{|l|c|c|c|}
\hline \multicolumn{1}{|c|}{ Age } & $\begin{array}{c}\text { No. of } \\
\text { patients }\end{array}$ & Male & Female \\
\hline $1-10$ & 10 & 8 & 1 \\
\hline $11-60$ & 82 & 44 & 18 \\
\hline$>61$ & 8 & 20 & 9 \\
\hline TOTAL & 100 & 72 & 28 \\
\hline
\end{tabular}

The most common mode of head injury was found to be road traffic accidents accounting for $68 \%$ of total and Fall from height and physical assaults being subsequent with $18 \%$ and $14 \%$ incidence respectively. (Table 2)

Table 2 - Mode of injury

\begin{tabular}{|l|l|l|}
\hline Mode of injury & No. of patients & $\%$ \\
\hline RTA & 68 & 68 \\
\hline Fall from height & 18 & 18 \\
\hline Assualts & 14 & 14 \\
\hline
\end{tabular}

Looking at the data, Glasgow coma scale at time of presentation to hospital was equal in distribution in $<8$ and $9-13$ groups with 36 patients in each group. Patients with GCS range of 9-13 showed significant improvement after post resuscitation (Table 3 ).

Table 3 - Glasgow coma scale at the time of presentation to hospital and Post resuscitation

\begin{tabular}{|l|c|c|}
\hline GCS & $\begin{array}{l}\text { No. of patients at the } \\
\text { Time of Arrival }\end{array}$ & $\begin{array}{l}\text { Post } \\
\text { Resuscitation }\end{array}$ \\
\hline$<8$ & 36 & 34 \\
\hline $9-13$ & 36 & 44 \\
\hline $14-15$ & 28 & 22 \\
\hline
\end{tabular}

Comparing others factors like pupillary abnormality, there was a significant (100\%) death among patients presented with bilateral pupil dilatation corresponding to 13 patients. Patients with normal pupil on presentation were 34 in numbers and out of which only 3 patients had mortality having a $9 \%$ distribution (Table 4).

Table 4 - Pupillary abnormalities

\begin{tabular}{|l|c|c|c|}
\hline Pupils & $\begin{array}{c}\text { No. of } \\
\text { patients }\end{array}$ & Mortality & $\%$ \\
\hline Normal pupils & 34 & 3 & 9 \\
\hline $\begin{array}{l}\text { Unilateral } \\
\text { dilated pupil }\end{array}$ & 53 & 18 & 34 \\
\hline $\begin{array}{l}\text { Bilateral } \\
\text { dilated pupil }\end{array}$ & 13 & 13 & 100 \\
\hline
\end{tabular}

Comparing Table 5, out of 42 patients who presented with contralateral Hemiparesis, 24 patients (57\%) had mortality, whereas only 10 patients of 58 died who presented with no neurological deficit. When Comparing hemodynamic status, patient had significant mortality when presenting with systolic BP of less than $90 \mathrm{mmHg}$ as compare to more than $90 \mathrm{mmHg}$ having $71.42 \%$ and $17 \%$ mortality in each (Table 6).

Table 5 - Focal neurological deficit

\begin{tabular}{|l|c|c|c|}
\hline $\begin{array}{l}\text { Neurological } \\
\text { deficit }\end{array}$ & $\begin{array}{c}\text { No. of } \\
\text { patients }\end{array}$ & Mortality & $\%$ \\
\hline $\begin{array}{l}\text { No neurological } \\
\text { deficit }\end{array}$ & 58 & 10 & 17 \\
\hline $\begin{array}{l}\text { Contralateral } \\
\text { hemiparesis }\end{array}$ & 42 & 24 & 57 \\
\hline
\end{tabular}

Table 6 - Hemodynamic status

\begin{tabular}{|l|c|c|c|}
\hline Bp & $\begin{array}{c}\text { No of } \\
\text { patients }\end{array}$ & Mortality & $\%$ \\
\hline $\begin{array}{l}\text { Systolic BP } \\
<90 \mathrm{mmhg}\end{array}$ & 28 & 20 & 71.42 \\
\hline $\begin{array}{l}\text { Systolic BP } \\
>90 \mathrm{mmhg}\end{array}$ & 78 & 14 & 17.95 \\
\hline
\end{tabular}


Table 7 and 8 shows incidence and mortality of patients as per neuroimaging that is CT scan, while table 7 illustrates mortality on the basis of hematoma thickness on the other hand Table 8 explains mortality on the basis of midline shift. Majority of patients came with a hematoma thickness of 5-10 mm corresponding to 40 in number with $14 \%$ mortality and the highest mortality rate was in patients presenting with more than $10 \mathrm{~mm}$ thickness with $19 \%$ mortality. Looking at Table 8, 66 patients of the total cases presented with midline shift of more than 5 $\mathrm{mm}$ with a significant mortality rate of $45.45 \%$.

Table 7 - CT scan thickness of hematoma

\begin{tabular}{|l|c|c|c|}
\hline $\begin{array}{l}\text { Thickness of } \\
\text { hematoma }\end{array}$ & $\begin{array}{c}\text { No of } \\
\text { patients }\end{array}$ & Mortality & $\%$ \\
\hline$<5 \mathrm{~mm}$ & 28 & 01 & 3.6 \\
\hline $5-10 \mathrm{~mm}$ & 40 & 14 & 35 \\
\hline$>10 \mathrm{~mm}$ & 32 & 19 & 59 \\
\hline
\end{tabular}

Table 8 - Midline shift

\begin{tabular}{|l|c|c|c|}
\hline Midline shift & $\begin{array}{c}\text { No. of } \\
\text { patients }\end{array}$ & Mortality & \%age \\
\hline$<5 \mathrm{~mm}$ & 34 & 04 & 11.76 \\
\hline$>5 \mathrm{~mm}$ & 66 & 30 & 45.45 \\
\hline
\end{tabular}

Our study population showed other associated intracranial injury which highest incidence of 32 patients having SDH with SAH corresponding to $53.13 \%$ on mortality scale on the other hand simple SDH corresponded to 26 cases with a $7.69 \%$ of mortality (Table 9).
Table 9 - Associated intra cranial injury

\begin{tabular}{|l|c|c|c|}
\hline $\begin{array}{l}\text { Associated } \\
\text { Injury }\end{array}$ & $\begin{array}{c}\text { No of } \\
\text { patients }\end{array}$ & Mortality & $\%$ \\
\hline Simple SDH & 26 & 02 & 7.69 \\
\hline $\begin{array}{l}\text { SDH with } \\
\text { EDH }\end{array}$ & 08 & 01 & 12.5 \\
\hline $\begin{array}{l}\text { SDH with } \\
\text { Contusion }\end{array}$ & 34 & 14 & 41.18 \\
\hline $\begin{array}{l}\text { SDH with } \\
\text { SAH }\end{array}$ & 32 & 17 & 53.13 \\
\hline
\end{tabular}

Looking at Glasglow Outcome Score at 4 weeks (Table 10), patients were divided into 5 grades from 1-5. There was equal distribution among grade $1(34 \%)$, grade $5(34 \%)$ and between grade $2(8 \%)$, grade $3(8 \%)$ patients with grade 4 having $16 \%$ patients.

Table 10 - Glasgow outcome scale at 4 week

\begin{tabular}{|l|c|c|}
\hline Grade & No. of patients & $\%$ \\
\hline 1 & 34 & 34 \\
\hline 2 & 08 & 08 \\
\hline 3 & 08 & 08 \\
\hline 4 & 16 & 16 \\
\hline 5 & 34 & 34 \\
\hline
\end{tabular}

Prognostic criteria was evaluated in all patients using Table 11 and patients were given score for each factor from 0 to 1 .Sum of total score (0 to 10) was calculated and patients were divided into 3 groups with score 1-5 in group 1, 6-8 in group 2 and 9-10 in group 3. Out of 42 patients in group 1, 22 patients were kept for conservative management and 20 were operated with $90.9 \%$ and $55 \%$ mortality in each. In group 2 with score of 6-8 there were total 24 patients out of which 15 patients were kept in conservative group with only $6.66 \%$ mortality and 9 patients out of 24 were operated with 
$22.2 \%$ mortality rate. When comparing group 3 with 9-10, both conservative and operative patients had zero mortality rate having 30 and 4 patients in each.

Table 11 - Gautam and Sharma

Clinicoradiological Prognostic Score (0 To 10)

\begin{tabular}{|l|l|l|}
\hline \multicolumn{1}{|c|}{ Prognostic Factors } & 0 & 1 \\
\hline GCS On Arrival in Hospital & $</=8$ & $>9$ \\
\hline $\begin{array}{l}\text { Hematoma Thickness (In mm)in } \\
\text { NCCT head on arrival }\end{array}$ & $>5$ & $<5$ \\
\hline $\begin{array}{l}\text { Presence And/ Or Degree Of } \\
\text { Midline Brain Shift (In mm) in } \\
\text { NCCT head on arrival }\end{array}$ & $>5$ & $<5$ \\
\hline $\begin{array}{l}\text { Increase in midline shift and } \\
\text { thickness of hematoma in repeat }\end{array}$ & Yes & No \\
\hline
\end{tabular}

\begin{tabular}{|l|l|l|}
\hline NCCT head after 6 hrs & & \\
\hline Pupil Abnormality & Yes & No \\
\hline Age & $>60$ & $<60$ \\
\hline $\begin{array}{l}\text { Availability Of OT, } \\
\text { Neurointensive Care,CT and } \\
\text { Other Facilities }\end{array}$ & No & Yes \\
\hline $\begin{array}{l}\text { Co-Morbidity And Associated } \\
\text { Trauma }\end{array}$ & Yes & No \\
\hline $\begin{array}{l}\text { Time To Arrival In Tertiary } \\
\text { Centre (In Hours) }\end{array}$ & $>6$ & $<6$ \\
\hline $\begin{array}{l}\text { Drop Of GCS In Subsequent } \\
\text { Examination }\end{array}$ & $>2$ & $<2$ \\
\hline
\end{tabular}

Table 12 - Management Of Acute subdural hematoma according to prognostic score

\begin{tabular}{|l|l|l|l|l|l|l|l|}
\hline \multirow{2}{*}{ Score } & Total no of & \multicolumn{4}{l|}{ Conservative } & \multicolumn{3}{l|}{ Operative } \\
\cline { 3 - 8 } & patients & Total & Mortality & \% Mortality & Total & Mortality & \% Mortality \\
\hline Score $9-10$ & 34 & 30 & 0 & 0 & 4 & 0 & 0 \\
\hline Score 6-8 & 24 & 15 & 1 & 6.67 & 9 & 2 & 22.2 \\
\hline Score $1-5$ & 42 & 22 & 20 & 90.9 & 20 & 11 & 55 \\
\hline
\end{tabular}

\section{Discussion}

Morbidity and mortality after an acute subdural haematoma are the highest of all traumatic mass lesions. This poor outcome results largely from associated parenchymal injuries and subsequent intracranial hypertension. [10] Of the many variables that have been found to significantly correlate either positively or negatively (Age, sex, GCS at the time of presentation, post resuscitation GCS, pupillary anisocoria, focal neurological deficit, hemodynamic status, imaging findings of thickness of hematoma, midline shift, simple SDH or complicated SDH,
Finding on repeat CT after 6 hrs, GCS at the time of discharge and at four weeks) with morbidity or mortality from acute subdural hematoma, [1,3] only two can potentially be affected by neurosurgical intervention: the time from injury to operative intervention for evacuation of hematoma and the control of ICP. Prompt surgical intervention for evacuation of traumatic intracranial hematomas has been emphasized in the literature but little hard evidence is available to support its efficacy. As advocated by us we believe that surgery should be performed as early as possible, especially in patients with Neuro-clinical and radiological prognostic 
score of 1-5 with hemodynamic stable patient and duration of arrival in hospital after trauma of less than $6 \mathrm{hrs}$ with no co-morbid conditions and in patients with Neuroclinical and radiological prognostic score of 6-10 with hemodynamic stable patient and duration of arrival in hospital after trauma of less than 6 hrs with no co-morbid conditions and hematoma thickness more than $10 \mathrm{~mm}$.

Isolated $\mathrm{ASDH}$, acting as a compressive lesion, is an uncommon clinicopathological entity. Majority of patients with ASDH have associated focal (contusion / laceration / intracerebral haematoma) or global (diffuse axonal injury, subarachnoid haemorrhage) involvement of the brain or both of these. In addition, ischaemia underlying the haematoma and ipsilateral hemispherical brain swelling (? hyperaemic, ? oedematous), which may be self perpetuating, are consistent findings in most patients with surgically significant haematoma. [8,9]

Kristianson and Tandon found 100\% mortality when pupils are dilated and fixed, $19 \%$ when they are unequal and $14 \%$ when pupils are normal 3 which is comparable to our study.

The factors affecting the prognosis of the patients with ASDH were assessed by ZhAO Hong as follows (1) Mechanism of injury. The primary causes of ASDH were fall (53\%), motor vehicle accidents (37\%), blunt impact injuries (4\%), and other factors (7\%). There was no significant difference in mortality and functional recovery rate regardless of injury mechanism. (2) Age, significant higher mortality is found in the patients over 65 years old. (3) Sex. In spite of a 3-to-1 male predominance, there was no significant difference in the prognosis between males and females. (4) Pupillary reflex. Bilateral absence of pupillary reflexs was associated with an $88 \%$ mortality and a $7 \%$ functional recovery rate. And (5) time from injury to operation which is comparable to our study. [11]

Age is a strong factor influencing both mortality and morbidity, as several authors have identified in their works. In our study confirms this result: there is a significant statistical correlation between age and patient's outcome. Despite some contradictions, most literature supports children faring better than adults who have severe brain injury. Gennereli et al found that interval between injury to surgery, hypotension and basal cistern obliteration are the three important factors, which have significant impact on outcome. Our study also found these three factors together have significant impact to the extent of $90 \%$ mortality. [4]

Heissler and Dietz et al found thickness of haematoma, midline shift are having significant impact on outcome. They found haematoma thickness of $>10 \mathrm{~mm}$ with midline shift $>5 \mathrm{~mm}$ are having $30 \%$ increased mortality than those without. Our study showed similar trend with mortality reaching 30\%. [4] In 1989, Howard, et al [5]., reported extremely favorable results in the management of acute subdural hematoma with the primary discriminating variables being age and clot size. In their patients aged 18 to 40 years, the mortality rate was only $18 \%$ with functional survival in $66 \%$ as 
compared to rates of $74 \%$ and $5 \%$, respectively, in those aged over 65 years. Even in young patients with low GCS scores the results were similarly encouraging: $25 \%$ mortality and $67 \%$ functional recovery which is comparable to our data [6].

\section{Conclusions}

We found that, the following factors are having significant influence on the outcome of acute sub dural hematoma in our study:

Gautam and Sharma Clinicoradiological Prognostic Score of 9-10 have favorable outcome and score 6-8 have good outcome with early intervention if required

Hypotension and associated intracranial or other injury are another factor which is having significant influence on the outcome after surgery for acute subdural hematoma.

This proposed Clinicoradiological Prognostic Score is useful in peripheral neurosurgery centre having limited resources. According to the results, use of Neuro-clinical and radiological prognostic scoring system is very useful in determining early intervention and also avoids unnecessary surgical intervention.

\section{Correspondence}

Dr S.N. Gautam, House no 63, Shrinathpuram, Sector B, Kota, Rajasthan-324010, India, +919413553530

\section{References}

1. Braakman R, Gelpke GJ, Habbema JDF, et al: Systematic selection of prognostic features in patients with severe head injury. Neurosurgery 6:362-370, 1980 2. D'AMATO, O. PIAZZA:Prognosis of isolated acute post-traumatic subdural haematoma J Neurosurg Sci 2007;51:00-00

3. Fell DA, Fitzgerald S, Moiel RH, et al: Acute subdural hematomas. Review of 144 cases. J Neurosurg 42: 3742,1975

4. Gennereli TA, et al. Influence of the type of intracraniallesion on outcome from severe head injury. J Neurosurg 1982;56(1):26-32.

5. Howard MA III, Gross AS, Dacey RG Jr, et al: Acute subdural hematomas: an age-dependent clinical entity. JNeurosurg 71:858-863,1989

6. JACK E. WILBERGER, JR.,MARK HARRI. Acute subdural hematoma: morbidity, mortality, and operative timing, J Neurosurg 74:212-218, 1991

7. Munro D: The diagnosis and treatment of subdural hematoma. A report of sixty-two cases. N Engl J Med 210: 1145-1158,1934

8. Tandon PN : Management of head injury: Fads, fashions and facts. Neurol India 1986; $34: 1$-30.

9. Tandon P N. Acute subdural haematoma : a reappraisal. Neurol India 2001;49:3-10

10. Raman KS, Ramamurthi B. Subdural haematoma. Neurol 1970;18:18.

11. ZhAO Hong and BAI Xiang-jun:Influence of operative timing on prognosis of patients with acute subdural hematoma: Chinese Journal of Traumatology 2009; 12(5):296-298 